\title{
Acanthosis nigricans in obese adolescents: prevalence, impact, and management challenges
}

This article was published in the following Dove Press journal:

Adolescent Health, Medicine and Therapeutics

16 December 2016

Number of times this article has been viewed

\author{
Hak Yung $\mathrm{Ng}$ \\ Department of Paediatrics and \\ Adolescent Medicine, Tseung Kwan O \\ Hospital, Tseung Kwan O, Hong Kong, \\ China
}

\begin{abstract}
Obesity in adolescence is a public health priority because it usually tracks into adulthood, resulting in enormous medical and social costs. This underscores the importance of early identification and intervention. Acanthosis nigricans (AN) was once considered a rare paraneoplastic dermatosis, but is now frequently observed in obese adolescents. Current understanding suggests that it is associated with insulin resistance and has a unique role in secondary prevention. The purpose of this narrative review is to provide a comprehensive overview of $\mathrm{AN}$ in obese adolescents, covering its history, current knowledge on the condition, its clinical significance, management challenges, and the direction of future research.

Keywords: Differential diagnosis, screening, insulin resistance, type 2 diabetes mellitus, metabolically healthy obesity, behavioral weight management, pharmacotherapy, bariatric surgery

\section{Introduction}

Acanthosis nigricans (AN) is a dermatological condition that has been recognized for more than a hundred years. It can signify a long list of possible underlying medical illnesses. Early on, it was known for its association with malignancy in the adult population. Recently, the focus on this cutaneous marker has shifted from internal malignancy to insulin resistance (IR). ${ }^{1,2} \mathrm{AN}$ occurs frequently in adolescents associated with obesity, a chronic illness that often begins in childhood and has a tremendous impact on an individual's future health. This narrative review discusses AN and its association with obesity in adolescents and focus on their clinical impact and management challenges, with the hope of raising awareness of this dermatosis in adolescents and leading to earlier identification and intervention for this at-risk group.
\end{abstract}

\section{AN: the historical perspective}

AN was first reported in the International Atlas for Rare Skin Diseases more than one hundred years ago. The term was proposed by Dr. Paul Gerson Unna from Hamburg and published in an 1891 case report by Dr. Sigmund Pollitzer. A similar case was described by Dr. Vitezslav Janovsky from Prague in the same issue., ${ }^{3,4}$

After the original independent reports of the first two patients, cases were initially identified in Europe. Most of the cases were associated with abdominal or pelvic cancers. ${ }^{3}$ Later, more patients with AN were reported to have no evidence of malignancy. Among the benign group, many associations were implicated. ${ }^{5}$ To complicate matters, various classifications have been proposed over the years..$^{4-12}$ The association of AN and obesity was first noted by Robinson et al in 1947; they reported a case of AN juvenilis
Correspondence: Hak Yung Ng Department of Paediatrics and Adolescent Medicine, Tseung Kwan O Hospital, No. 2 Po Ning Lane, Hang Hau, Tseung Kwan O, Hong Kong, China Tel +852 22080 I II

Email nghypatrick@gmail.com
Adolescent Health, Medicine and Therapeutics 2017:8 I-10

(c) (1) (8) ๑ $2017 \mathrm{Ng}$. This work is published and licensed by Dove Medical Press Limited. The full terms of this license are available at https://www.dovepress.com/terms.

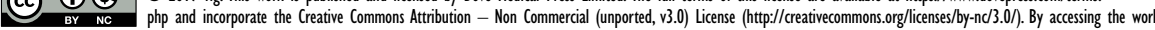
you herbby accept the Terms. Non-commercial uses of the work are permitted without any further permission from Dove Medical Press Limited, provided the work is properly attributed. For permission for commercial use of this work, please see paragraphs 4.2 and 5 of our Terms (https://www.doveperss.com/terms.php). 
associated with obesity in a 17-year-old boy. They also presented a compilation of 10 cases from the medical literature. ${ }^{13}$

In parallel with the recent pandemic of obesity, obesityassociated AN has become the most common and important cause of AN. ${ }^{14,15}$ This is particularly true in the pediatric population. ${ }^{5}$ This review is limited to obesity-associated AN in children and adolescents.

\section{Current knowledge on AN}

In general, there is no sex predilection with AN., ${ }^{5,12,16,17}$ In Texas, among an unselected group of 1412 adolescents with an obesity rate of $27.1 \%$, Stuart et al found AN in $7.1 \% .{ }^{18} \mathrm{In}$ another convenience sample of 675 middle school students from New Mexico, Mukhtar et al found AN in $18.9 \%$ of the students screened. These students were aged between 12 and 15 years, and the obesity rate was $26.8 \%$ using the definition of body mass index (BMI) $>25 \mathrm{~kg} / \mathrm{m}^{2} .{ }^{19}$

The prevalence of AN ranges from $49.2 \%$ to $58.2 \%$ in various international studies involving children or adolescents with obesity (Table 1) ${ }^{19-22}$ The prevalence will be even higher in patients with severe obesity, in certain high-risk ethnic groups or in patients already diagnosed with type 2 diabetes mellitus (T2DM). ${ }^{23}$

Studies have found that this dermatosis is more common in adolescents than in younger children. IR is also more severe in older children. ${ }^{20,22}$ This can be explained by the longer duration of being obese and having IR with puberty. The prevalence of $\mathrm{AN}$ is also higher in obese children than in overweight ones. ${ }^{22,24}$

AN is characterized by symmetrical darkening and thickening of the skin. The involved skin appears light brown to black in color, depending on the patient's skin color and the degree of involvement (Figure 1). It is poorly marginated with accentuation of skin markings, giving rise to a roughened, velvety texture (Figures 2-4). As the lesion progresses, it may become papillomatous or verrucous plaques. ${ }^{12,25} \mathrm{AN}$ is typically asymptomatic, although it can sometimes be pruritic. ${ }^{4,14}$ The onset of AN is insidious. It frequently goes unnoticed or is simply mistaken as dirt by the patient and the family., 56,27

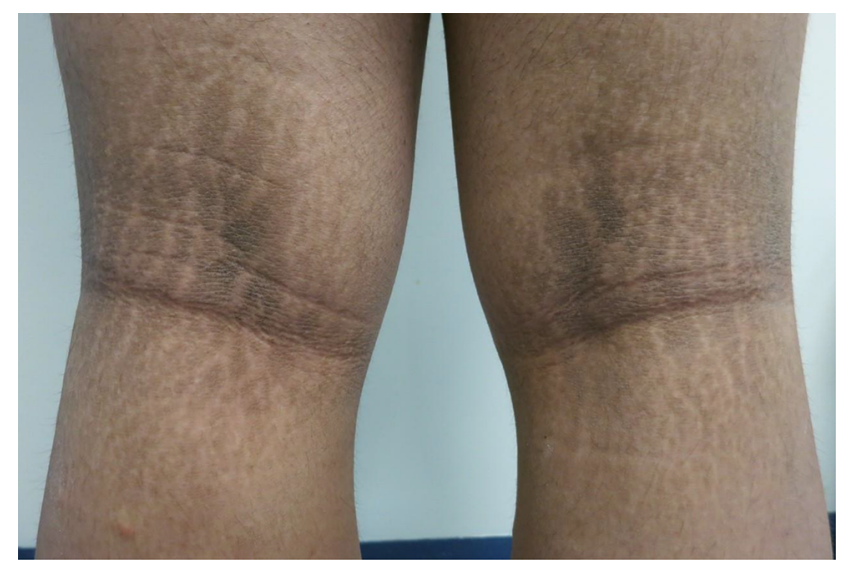

Figure I Acanthosis nigricans and striae over the popliteal fossa.

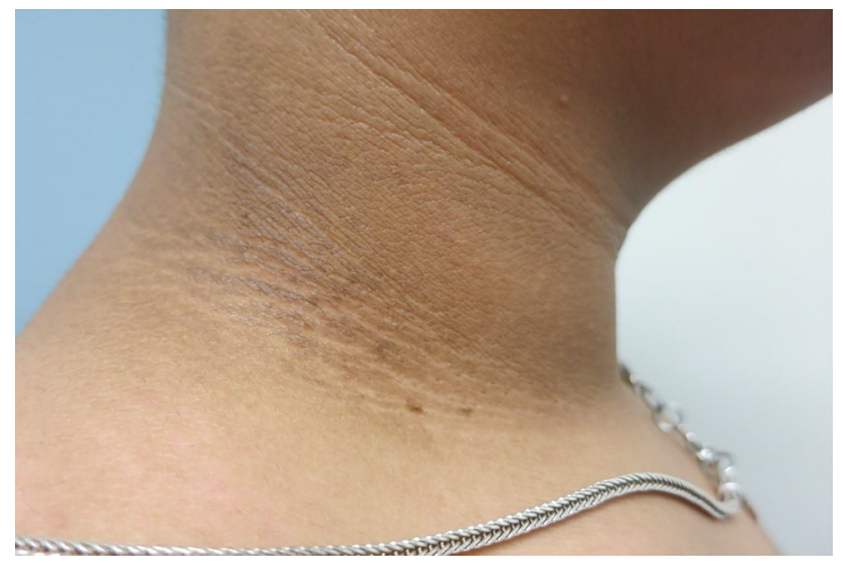

Figure 2 Acanthosis nigricans and skin tags on the neck.

AN can affect any part of the skin, but common sites include the neck, axillae, groin, and anogenital areas. ${ }^{1,3,4} \mathrm{In}$ contrast, the face, eyelids, supra-alar nasal creases, inner thigh, antecubital fossa, popliteal fossa, umbilicus, palms, soles, knuckles (Figure 5), nipples, and areolas are less frequently involved areas. ${ }^{25,28}$ The neck and axillae are frequently involved and are sites that are more socially acceptable than others for screening. Mucosal involvement is rare in obesity-associated $\mathrm{AN}$; it is more common in malignancy-associated cases. ${ }^{4,12}$

In a recent study involving a group of medical students from Mexico, AN at the knuckles was found to be relatively

Table I Prevalence of AN in studies involving children or adolescents with obesity

\begin{tabular}{|c|c|c|c|c|c|c|}
\hline Publication/year & Location & Sample (N) & Age (years) & $\operatorname{Sex}(M / F)$ & Overweight/obese & Prevalence (\%) \\
\hline \multirow[t]{2}{*}{ Kluczynik et al $(2012)^{20}$} & Brazil & 194 & $2-19$ & $66 / 128$ & 30 (BMI\% 85\%-95\%) & 58.2 \\
\hline & & & & & I 64 (BMI\% >95\%) & \\
\hline \multirow[t]{2}{*}{ Shalitin et al $(2005)^{21}$} & Israel & 256 & $5-22$ & $109 / 147$ & 22 (BMI\% 85\%-95\%) & 56.6 \\
\hline & & & & & 234 (BMI\% >95\%) & \\
\hline \multirow[t]{2}{*}{$\mathrm{Ng}$ et al $(2014)^{22}$} & Hong Kong & 543 & $5-18$ & $346 / 197$ & I24 (BMI\% 90\%-97\%) & 54.0 \\
\hline & & & & & 419 (BMI\% >97\%) & \\
\hline Mukhtar et al $(2001)^{19}$ & New Mexico & $|8|$ & $12-15$ & Not stated & I8I (BMI >25 kg/m²) & 49.2 \\
\hline
\end{tabular}

Abbreviations: AN, acanthosis nigricans; M, male; F, female; BMI, body mass index. 


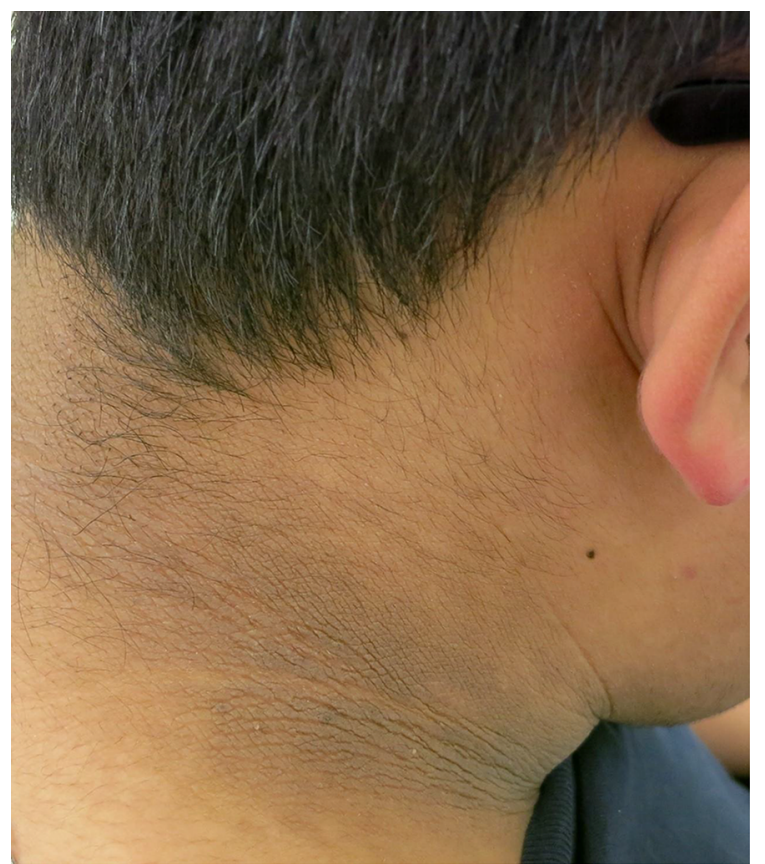

Figure 3 The neck displays coarse, thickened and hyperpigmented skin, with accentuation of skin markings.

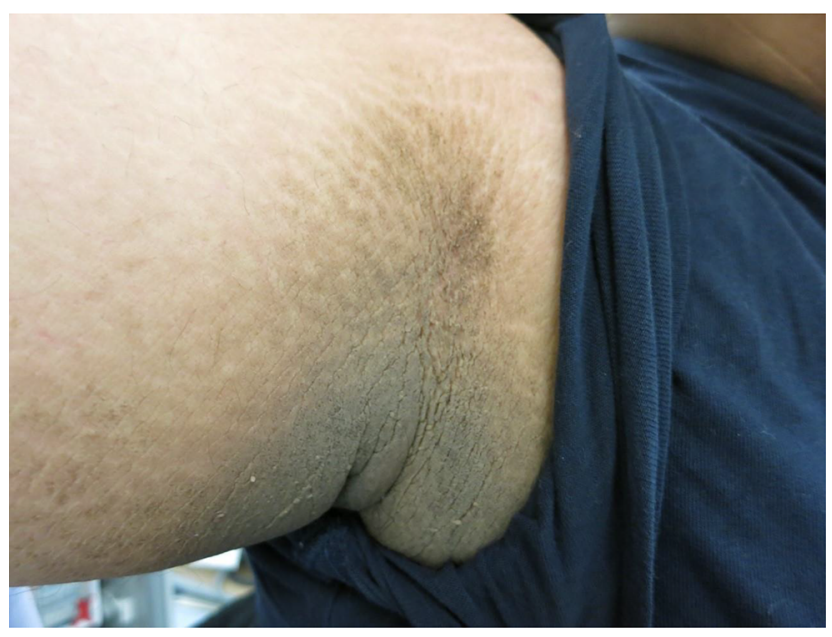

Figure 4 This image illustrates darkening and thickening of the skin at the axilla giving rise to a roughened, velvety appearance.

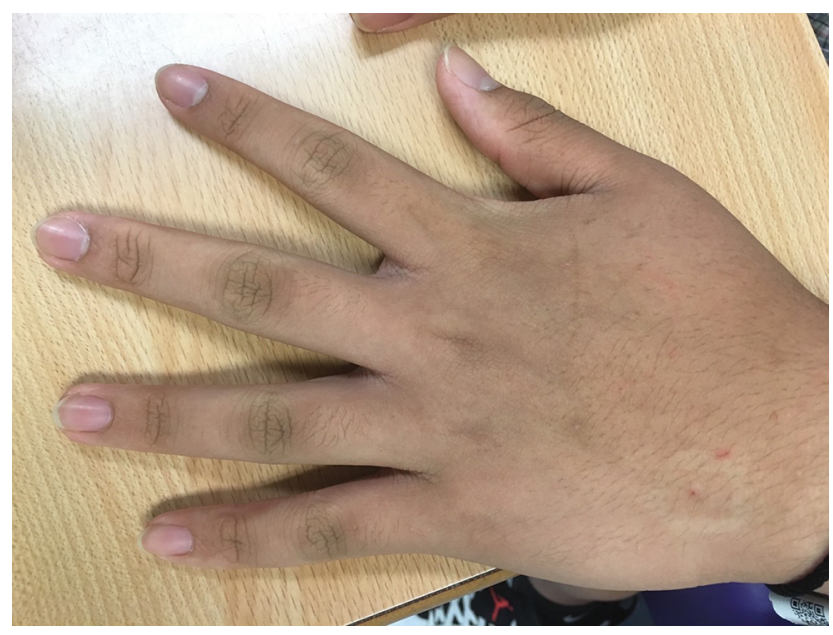

Figure 5 Acanthosis nigricans on the knuckles. common and to even occur before the onset of obesity in that cohort. It was proposed as a good clinical indicator of underlying IR. ${ }^{29}$ This obviously requires more confirmatory research.

The diagnosis of AN is usually a clinical one. In most case, it is not particularly difficult given its characteristic appearance. In uncertain cases, a skin biopsy may be of help. The histopathology typically shows epidermal hyperkeratosis and papillomatosis. Areas of minimal to mild acanthosis may alternate with spotty areas of apparent atrophy in the epidermis. The pigmentation usually comes from epidermal hyperkeratosis, although increased melanin may also be found in the stratum corneum. Dermal inflammatory infiltrate is usually absent. Upward projection of the dermal papillae in a finger-like fashion may be seen., ${ }^{4,510,12}$

The exact pathogenesis of obesity-associated AN is complicated and has yet to be fully elucidated. ${ }^{9,30}$ The most commonly proposed mechanism is the direct and indirect activation of the insulin-like growth factor receptor by hyperinsulinemia, triggering dermal fibroblast, and epidermal keratinocyte proliferation. ${ }^{12,14,30}$ The preferential location of AN suggests friction, and perspiration may also play a role in the pathogenesis. . $^{15,31-33}$

AN has rarely been reported in patients receiving insulin injections. It has been postulated to be a local cutaneous side effect of injected insulin. ${ }^{34-36}$ This observed phenomenon further supports the proposed pathogenesis of AN, the stimulation of insulin-like growth factor receptors by hyperinsulinemia. ${ }^{37}$

Obesity-associated AN was once labeled "pseudoacanthosis nigricans." This is a misnomer as it is true AN, although some authors have suggested that it is a histologically milder form..$^{4,78-41}$ To avoid confusion, however, usage of the terms "pseudoacanthosis nigricans" should be discouraged. AN associated with malignancy is very rare in childhood. ${ }^{11}$ The new occurrence of AN in an adolescent with obesity should prompt a search for IR instead of malignancy.

In 1986, Stuart et al first proposed an "acanthosis score" to quantify the degree of $\mathrm{AN} .{ }^{42}$ The score was based on the degree of involvement, ranging from 0 to 4 , in five specific areas. In 1992, Hud et al attempted to provide more specific descriptions of the severity based on the texture. ${ }^{43}$

In 1999, Burke et al developed a visual scale with high interobserver reliability in a cohort of Mexican Americans. The proposed scale assessed the degree of severity over the neck and correlated well with BMI and fasting insulin level. ${ }^{44}$ However, skin phototype may influence the diagnostic value of AN for IR..$^{45}$ Thus, the use of AN severity scoring for IR assessment is not straightforward. 
Furthermore, Kobaissi et al found that little clinically relevant information was gained from scoring AN severity using a scale. They proposed the use of just the presence or absence of AN as a simple way of determination. ${ }^{46}$ The simple categorization of $\mathrm{AN}$ as present or absent would obviously improve its clinical usage.

Brickman et $\mathrm{a}^{23}$ found a minimal role for digital photography in AN scoring or classification. The technical issue of obtaining sharp photographs with comparable magnification under different lighting sources was difficult. Detection of subtle texture changes on photographs also posed significant challenges for achieving satisfactory agreement. $^{23}$

Medical equipment using diffuse reflectance spectroscopy and colorimetry is still experimental. ${ }^{47}$ As technology advances, perhaps more convenient and affordable equipment offering high sensitivity and specificity for evaluating AN will be available for clinical use.

\section{Conditions that may be confused with AN}

Morphological similarities to certain other cutaneous diseases may contribute to diagnostic confusion. Epidermal nevi, psoriasis, and fungal and candidal infections are some conditions that may be mistaken for $\mathrm{AN},{ }^{5}$ and "atopic dirty neck" is another condition, which was first described in 1987 by Colver et al. ${ }^{48}$ It is called acquired atopic hyperpigmentation by some authors and is common in patients with atopic dermatitis. The onset is usually in adolescence, and neck is the typical site of involvement, although other flexural areas are also involved in $30 \%$ of cases. $^{49}$

Confluent and reticulated papillomatosis is a rare dermatosis that may also be confused with AN. ${ }^{50}$ It is a disorder of keratinization involving mainly the trunk and neck. Clinically, there are hyperkeratotic papules that coalesce into confluent plaques with a reticular pattern in the periphery. ${ }^{51}$

Hailey-Hailey disease, or familial benign chronic pemphigus, is another rare intertriginous dermatosis. It is a blistering disorder that presents with painful erosions and cracks over the flexures. The typical age of onset is usually between 20 and 40 years. ${ }^{52}$

Terra firma-forme dermatosis is considered a keratinocyte retention disorder which is slightly more common in children and adolescents. It presents as an asymptomatic hyperpigmented patch which is indistinguishable from dirt. It can only be removed by $70 \%$ isopropyl alcohol, not usual hygiene measures. ${ }^{53-55}$ This serves both diagnostic and therapeutic purposes.

\section{Obesity in adolescents}

The prevalence of childhood and adolescent obesity is well known to be increasing in high-income countries over the past few decades. Although the rise might plateau in some countries, the prevalence is still considered unacceptably high. Even more concerning is evidence showing its rapid rise in low- and middle-income countries. ${ }^{56}$

In June 2013, the American Medical Association declared obesity to be "a disease." ${ }^{57}$ This caused much discussion on whether classifying obesity as a disease would really be beneficial..$^{58-63}$ On the one hand, it could lead to reduced discrimination, possible insurance coverage in some countries, and increased funding for medical research. ${ }^{59} \mathrm{On}$ the other hand, the "medicalization" of obesity may result in a loss of the concept of personal control and a reliance on medication and surgery. ${ }^{62,64}$

Generally, obesity is a consequence of the energy imbalance when intake exceeds requirement. ${ }^{65,66}$ However, this is an over-simplified explanation of a complex condition that is related to genetic predispositions, human behavior, environmental factors, and policy interventions..$^{61,67-71}$ Furthermore, epigenetic modifications, gut flora, viral infection, and psychological factors may all be implicated in its pathogenesis. $^{72,73}$

Obesity in adolescence is a public health priority because it usually tracks into adulthood. ${ }^{65,74-78}$ The risk for obesity in adulthood is at least five times higher for individuals who are already obese in their youth. ${ }^{75}$ The degree of tracking is even more pronounced among the heaviest youth; they are more likely to develop severe obesity in adulthood. ${ }^{79}$ Once severe obesity is established in adolescence, some authors believe that nonsurgical treatment is virtually ineffective. ${ }^{78}$

Strong evidence suggests that obesity in childhood is not a transient developmental phenomenon. Instead, it exerts sustained adverse effects over the whole life span if it is not tackled..$^{76,77,80,81}$ Fortunately, cardiovascular risk can be markedly reduced to a level similar to that of a healthy individual if the obese adolescent can become a nonobese adult. ${ }^{77}$ Health benefits may start to be appreciated with as little as a $5 \%$ sustained reduction of the initial body weight. ${ }^{82}$ This highlights the extreme importance of active prevention and management of childhood obesity. However, primary care practitioners, including general practitioners, pediatricians, and nurses, may be reluctant to deal with obesity in adolescence. A lack of competency, knowledge, time, training, and reimbursement are all contributory. ${ }^{83}$

Obesity has long been associated with negative descriptive stereotypes, such as lazy, noncompliant, incompetent, unintelligent, dishonest, weak-willed, annoying, 
undisciplined, and careless. ${ }^{84,85}$ Weight bias, discrimination, and stigmatization against obese individuals are widespread. This is true across different social contexts, including education and employment opportunities, mass media advertising, and even health care encounters. ${ }^{86}$ Weight discrimination is increasing and has become pervasive. As a result, it produces significant consequences for the physical and psychological health of individuals. ${ }^{85}$

Adolescence is a time for developing autonomy from parents. Adolescents are entitled to ad libitum access to food choices of their own while they are still less able than adults to self-regulate caloric intake. This is particularly risky for excessive weight gain in light of hormonal and physical changes associated with puberty. Fortunately, adolescence is still a period of susceptibility for intervention, making it a high-reward stage for obesity prevention. ${ }^{87}$

Family involvement is an important part of obesity management. ${ }^{65}$ Parents are encouraged to serve as authoritative role models and to offer a healthy home environment as much as possible. Provided the greater independence of adolescents, clinicians should also discuss the health-promoting behavior directly with them. ${ }^{88}$ Although we strive to promote personalized therapies, we must avoid making them feel different from their peers. A delicate balance between these two perspectives is important for treatment success. ${ }^{64}$ Adolescents are keen to develop their own ideas and identity. They may develop psychological resistance if they think they are being pushed and steered in a certain direction. ${ }^{89}$

Peers are important in the lives of adolescents. They can have substantial influence on diet and activity levels. Adolescents and their peers can be influenced by each other in both positive and negative ways..$^{90}$ Adolescent peer influence has been studied extensively. Selection and socialization effects are proposed to be the core of health risk behaviors. Evidence has also suggested that adolescents tend to conform to peers' weight-related behaviors. ${ }^{91}$

\section{The impact of AN on obese adolescents}

Treatment of obesity and its associated comorbidities is usually difficult and frustrating, for both clinicians and patients. ${ }^{92}$ The identification of individuals who may benefit most from early intervention is valuable in daily clinical practice. Screening for comorbidities in adolescents with obesity is needed, but difficult. Most guidelines suggest an individualized approach for ordering additional laboratory assessments. Risk factors such as race, family history, physical signs, and maternal history of gestational diabetes mellitus should be assessed before proceeding. ${ }^{93}$
In a sample of US eighth-grade students consisting of a high proportion (50\%) of overweight/obese adolescents (BMI $\geq 85^{\text {th }}$ percentile), AN was found to increase the likelihood of dysglycemia by $50 \%-100 \%$, even with adjustment for BMI and pubertal development. This suggests that AN imposes additional risk for dysglycemia over that from obesity alone. Hence, Rafalson et al concluded that AN is an easily identifiable clinical marker of impaired glucose tolerance and high-risk glycated hemoglobin. ${ }^{32}$ However, although most studies report that $\mathrm{AN}$ is a clinical indicator of underlying IR, some authors believe that AN is not an independent marker of IR. ${ }^{94,95}$

IR and obesity are strongly related to T2DM. T2DM was considered a disease of the elderly in the last century, whereas it is increasingly common to encounter T2DM in adolescents today. ${ }^{96}$ T2DM in childhood is often asymptomatic for a period of time. The transition through the stage of prediabetes to T2DM in children is believed to be faster than that in adults. ${ }^{97}$ This occurs over $5-10$ years in adults, whereas it has been reported to occur in only 12-21 months in children. ${ }^{97,98}$ In the author's clinical practice, a 15-year-old obese girl progressed from prediabetes to T2DM in only 4 months' time. This accelerated process highlights the importance of early identification of the prediabetes stage as there is strong evidence that weight management can delay progression from prediabetes to frank diabetes. ${ }^{82}$

Interestingly, many parents do not perceive a weight problem in their children. ${ }^{99}$ This could be due to a lack of knowledge or may simply represent a defense mechanism. Studies have found that parents who appreciate the weight status of their children are more likely to report intention to change, although that may not necessarily equate to behavior change. ${ }^{100}$ Even more confusing to parents, the news and some research studies have reported that obese individuals can still be "metabolically healthy." Metabolically healthy obesity (MHO) is a term that has attracted much attention over the last 10 years. So far, the definition of this phenotype varies, and no consensus has been reached, even for adults. ${ }^{101-103}$ Some authors suggest that MHO is simply a myth and that no level of obesity should be considered healthy. ${ }^{104,105}$

In the last 2 decades, many authors promulgate the usage of AN as an identifying sign for a group at high risk for metabolic abnormalities. ${ }^{15-17,106-116} \mathrm{BMI}$ is useful only if it is calculated and plotted on the appropriate growth chart. Overweight may be missed visually if it is not extreme. ${ }^{117}$ The clinical practice guideline of the American Academy of Pediatrics included AN as clinical evidence of IR. ${ }^{118}$ The latest recommendation of the American Diabetes Association endorsed the use of $\mathrm{AN}$ as one of the risk factors for testing 
asymptomatic overweight children. ${ }^{119}$ The presence of AN is a strong visual cue that may aid early detection of underlying cardiometabolic disease. ${ }^{20,117}$

AN screening over the neck and axilla is simple and noninvasive and is particularly valuable for use in adolescence to identify high-risk individuals. ${ }^{19}$ Identifying them may allow early implementation of interventions that can attenuate the development of diabetes and other comorbidities. ${ }^{120}$

AN can itself be a reason for seeking medical attention in adolescence. Adolescents may change their clothing styles to cover it. The unsightly appearance of AN may arouse significant psychological distress. That noted, AN can also be an important motivating factor for pursuing lifestyle changes. ${ }^{23}$

Additionally, screening children with AN may even help to identify parents with a higher risk for diabetes. UrrutiaRojas et al suggested using the AN status as a criterion to develop focused family screening. ${ }^{121}$

AN may develop prior to the onset of obesity. Wang et al suggested that certain genetic variants in the insulin-like growth factor receptor pathway contribute to this clinical observation. ${ }^{122}$ Some authors have suggested that the presence of AN on the knuckles of any normal weight patient might represent an early manifestation of IR..$^{29}$

The extent and severity of AN can parallel the degree of IR. ${ }^{12}$ With significant weight loss and increased physical activity, AN may lessen. However, one should be aware that AN can also lessen when insulin secretion decreases with diabetes. ${ }^{23}$

\section{Management challenges}

AN is a skin condition that is difficult to treat. ${ }^{123}$ Various topical agents (vitamin D analogs, retinoids, ammonium lactate, trichloroacetic acid, triple-combination depigmentation cream, urea, podophyllin, and salicylic acid) have been reported to have variable cosmetic results. ${ }^{12,14}$ Dermabrasion or laser therapy can also be attempted. ${ }^{12,123}$ Oral retinoids can normalize epithelial differentiation and growth, but high doses and prolonged courses of treatment are required. ${ }^{14}$ It is worth noting that purely dermatologic therapies that do not target the underlying condition are of transient benefit only. ${ }^{124}$

Management of obesity-associated AN may sound simple - just treat the underlying cause - but it rarely is. If the obesity and the associated IR improve, the cutaneous features of AN can regress. ${ }^{4,12,14,125}$ Thus, obesity management is crucial for tackling the problem.

The treatment of adolescent obesity has been largely neglected compared with adult obesity. ${ }^{126}$ Various international guidelines for the treatment of pediatric obesity; however, suggest an individualized, stepwise approach. ${ }^{127}$
Behavioral weight management comprises diet, exercise, and behavior modification to encourage sustained lifestyle changes. Although this remains the cornerstone of obesity management, it usually produces modest effects with relatively high attrition rates, leaving most of the adolescents obese..$^{79,126}$

The use of pharmacotherapy as an adjunct to behavioral weight management is essential in selected cases, but options are limited. The only Food and Drug Administration (FDA)approved drug for use in adolescents aged 12-16 years is orlistat (Xenical). ${ }^{128}$ It has been on the market since 1990 and has been available in the US as a nonprescription drug since $2007 .{ }^{129}$ The mechanism of action of orlistat, a lipase inhibitor, is fat malabsorption. Fat-soluble vitamin supplements are therefore recommended. ${ }^{127}$ The side effects of flatulence and steatorrhea contribute to a median discontinuation rate of $\sim 30 \%$ in most studies. These, together with the small amount of mean weight loss, make it an unattractive option. ${ }^{129}$

Metformin (Glucophage), a biguanide derivative, has FDA approval for use in childhood T2DM, but not in childhood obesity. It has a good safety track record, and the only common side effects are mild nausea and vomiting. Most studies in children and adolescents have shown modest reductions in body weight. ${ }^{79}$ Several mechanisms of action have been proposed, even though the exact mechanism at the molecular level is not yet fully understood. ${ }^{130}$ Off-label use of metformin is increasing in obese children. In the UK, a study published in 2012 found that the rate of unlicensed use of metformin in children and adolescents for obesity was $7.6 \%{ }^{131}$ Large-scale randomized controlled trials are needed before any recommendation for metformin usage in obese adolescents can be made. ${ }^{130}$

Given the limited success of behavioral weight management with or without pharmacological therapy, bariatric surgery is gaining favor around the world. In the adult population, bariatric surgery is the most effective treatment modality for obesity and its comorbidities. ${ }^{132}$ In adolescence, considerable evidence is available to suggest a clinical effect of bariatric surgery in carefully selected candidates. ${ }^{133-135}$ However, this remains a last resort, in view of the irreversibility, lack of long-term pediatric outcome data, risk of nutritional deficiencies, and possible need of reoperation. ${ }^{134}$ In addition, it is also linked to many ethical and moral considerations. ${ }^{136,137}$ With time, more data regarding the long-term outcome of pharmacotherapy and surgery will be available. Hopefully, the widespread resistance to these treatment options will abate. ${ }^{78}$

Advancements in technology may help the management of childhood obesity. ${ }^{76,138}$ Technology-based intervention is an 
important component of obesity management in adolescence. Technologies targeting diet and exercise have been shown to be effective in this population, although results have varied. ${ }^{90}$ Wearable fitness trackers are helpful in engaging adolescents in daily physical activities. They can keep track of periods of activity and inactivity throughout the day. Social media, text messaging, and online information are health information sources that adolescents prefer and believe. ${ }^{138}$

\section{Future research directions}

Despite many research studies on AN and obesity, many questions remain unanswered. Basic science and epidemiological studies are important cornerstones of obesity research. High-quality randomized controlled clinical trials are urgently needed to guide the prevention and treatment of this complex and multifaceted condition. ${ }^{58} \mathrm{New}$ innovations are very much needed to address this old problem. Research to find evidence-based interventions for both clinicians and policymakers is important. ${ }^{59}$

The skin phototypes, genetic makeup, and epigenetic factors obviously differ among different ethnic groups and countries. These factors will influence the prevalence and clinical usefulness of AN. Research focused on AN and underlying cardiometabolic comorbidities should preferably be carried out and interpreted with consideration of these factors. Longitudinal studies are essential to understand the health impact of $\mathrm{AN}$ in adolescents.

\section{Conclusion}

Childhood and adolescent obesity is still an alarming problem worldwide. The medical and social cost of childhood obesity will be huge in the years to come. Adolescence is a unique developmental period during which adoption of health behaviors is still possible. It provides an excellent opportunity to develop positive health attitudes and reform negative ones. $\mathrm{AN}$ has been reported in the medical literature for more than a hundred years. In recent years, the focus of research has shifted to its pathogenesis and identification of obese individuals at risk of comorbidities. By raising the awareness of this dermatosis, it is hoped that medical professionals can better combat obesity and its comorbidities.

\section{Disclosure}

The author reports no conflicts of interest in this work.

\section{References}

1. Hermanns-Le T, Hermanns JF, Pierard GE. Juvenile acanthosis nigricans and insulin resistance. Pediatr Dermatol. 2002;19(1):12-14.
2. Flier JS. Metabolic importance of acanthosis nigricans. Arch Dermatol. 1985;121(2):193.

3. Pollitzer S. Acanthosis nigricans: a symptom of a disorder of the abdominal sympathetic. J Am Med Assoc. 1909;53(17):1369-1373.

4. Schwartz RA. Acanthosis nigricans. JAm Acad Dermatol. 1994;31(1): 1-19.

5. Sinha S, Schwartz RA. Juvenile acanthosis nigricans. J Am Acad Dermatol. 2007;57(3):502-508.

6. Curth HO. Classification of acanthosis nigricans. Int J Dermatol. 1976; 15(8):592-593.

7. Anscombe A, Fox H, Gunn A. Acanthosis nigricans. Br J Surg. 1967; 54(6):525-529.

8. Williams DS. Acanthosis nigricans. J Insur Med . 2005;37(2):166.

9. De Sanctis V, Soliman A, Marsciani A, et al. Acanthosis nigricans in adolescents: a practical approach. Georgian Med News. 2013(222):73-78.

10. Uyttendaele H, Koss T, Bagheri B, et al. Generalized acanthosis nigricans in an otherwise healthy young child. Pediatr Dermatol. 2003; 20(3):254-256.

11. Skiljevic DS, Nikolic MM, Jakovljevic A, Dobrosavljevic DD. Generalized acanthosis nigricans in early childhood. Pediatr Dermatol. 2001;18(3):213-216.

12. Kutlubay Z, Engin B, Bairamov O, Tuzun Y. Acanthosis nigricans: a fold (intertriginous) dermatosis. Clin Dermatol. 2015;33(4):466-470.

13. Robinson SS, Tasker S. Acanthosis nigricans juvenilis associated with obesity: report of a case, with observations on endocrine dysfunction in benign acanthosis nigricans. Arch Dermatol Syphilol. 1947;55(6):749-760.

14. Phiske MM. An approach to acanthosis nigricans. Indian Dermatol Online J. 2014;5(3):239-249.

15. Rafalson L, Eysaman J, Quattrin T. Screening obese students for acanthosis nigricans and other diabetes risk factors in the urban school-based health center. Clin Pediatr. 2011;50(8):747-752.

16. Brown B, Noonan C, Bentley B, et al. Acanthosis nigricans among Northern Plains American Indian children. J Sch Nurs. 2010;26(6): 450-460.

17. Abraham C, Rozmus CL. Is acanthosis nigricans a reliable indicator for risk of type 2 diabetes in obese children and adolescents? A systematic review. J Sch Nurs. 2012;28(3):195-205.

18. Stuart CA, Pate CJ, Peters EJ. Prevalence of acanthosis nigricans in an unselected population. Am J Med. 1989;87(3):269-272.

19. Mukhtar Q, Cleverley G, Voorhees RE, McGrath JW. Prevalence of acanthosis nigricans and its association with hyperinsulinemia in New Mexico adolescents. J Adolesc Health. 2001;28(5):372-376.

20. Kluczynik CE, Mariz LS, Souza LC, Solano GB, Albuquerque FC, Medeiros CC. Acanthosis nigricans and insulin resistance in overweight children and adolescents. An Bras Dermatol. 2012;87(4):531-537.

21. Shalitin S, Abrahami M, Lilos P, Phillip M. Insulin resistance and impaired glucose tolerance in obese children and adolescents referred to a tertiary-care center in Israel. Int J Obes. 2005;29(6): 571-578.

22. Ng HY, Young JH, Huen KF, Chan LT. Acanthosis nigricans in obese Chinese children. Hong Kong Med J. 2014;20(4):290-296.

23. Brickman WJ, Binns HJ, Jovanovic BD, et al. Acanthosis nigricans: a common finding in overweight youth. Pediatr Dermatol. 2007;24(6):601-606

24. Nsiah-Kumi PA, Beals J, Lasley S, et al. Body mass index percentile more sensitive than acanthosis nigricans for screening Native American children for diabetes risk. J Natl Med Assoc. 2010;102(10):944-949.

25. Hermanns-Le T, Scheen A, Pierard GE. Acanthosis nigricans associated with insulin resistance: pathophysiology and management. $\mathrm{Am} J$ Clin Dermatol. 2004;5(3):199-203.

26. Gilkison C, Stuart C. Assessment of patients with acanthosis nigricans skin lesion for hyperinsulinemia, insulin resistance and diabetes risk. Nurse Pract. 1992;17(2):26-28.

27. Ponder SW, Anderson MA. Childhood obesity: practical considerations for prevention and management. Diabetes Spectr. 2007;20(3):148-153. 
28. Guffey D, Narahari S, Alinia H. Hyperpigmented plaques of the alar crease: an unusual presentation of acanthosis nigricans. Pediatr Dermatol. 2016;33(2):e160-e161.

29. Gomez-Flores M, Gonzalez-Saldivar G, Santos-Santos O, ÁlvarezVillalobos N, Rodríguez-Gutiérrez R, Tellez-Hinojosa C, GonzálezGonzález J. Implications of a clinically ignored site of acanthosis nigricans: the knuckles. Exp Clin Endocrinol Diabetes. 2015;123(1): 27-33.

30. Romo A, Benavides S. Treatment options in insulin resistance obesity-related acanthosis nigricans. Ann Pharmacother. 2008;42(7): 1090-1094.

31. Schilling WH, Crook MA. Cutaneous stigmata associated with insulin resistance and increased cardiovascular risk. Int J Dermatol. 2014;53(9):1062-1069.

32. Rafalson L, Pham TH, Willi SM, Marcus M, Jessup A, Baranowski $\mathrm{T}$. The association between acanthosis nigricans and dysglycemia in an ethnically diverse group of eighth grade students. Obesity (Silver Spring). 2013;21(3):E328-333.

33. Barabash-Neila R, Freire LR, Zulueta-Dorado T, Conejo-Mir J. Thickening of the skin on the forehead: a quiz. Acanthosis nigricans with forehead location. Acta Derm Venereol. 2011;91(1):108-110.

34. Buzási K, Sápi Z, Jermendy G. Acanthosis nigricans as a local cutaneous side effect of repeated human insulin injections. Diabetes Res Clin Pract. 2011;94(2):e34-e36.

35. Fleming MG, Simon SI. Cutaneous insulin reaction resembling acanthosis nigricans. Arch Dermatol. 1986;122(9):1054-1056.

36. Sawatkar GU, Dogra S, Bhadada SK, Kanwar AJ. Acanthosis nigricans - an uncommon cutaneous adverse effect of a common medication: report of two cases. Indian J Dermatol Venereol Leprol. 2013;79(4):553.

37. Brockow K, Steinkraus V, Rinninger F, Abeck D, Ring J. Acanthosis nigricans: a marker for hyperinsulinemia. Pediatr Dermatol. 1995;12(4):323-326.

38. Curth HO. Significance of acanthosis nigricans. AMA Arch Dermatol Syphilol. 1952;66(1):80-100.

39. Tighe S. Pseudoacanthosis nigricans. Lancet. 1960;276(7166): 1422-1423.

40. Akkash L, Badran D, Al-Omari AQ. Terra Firma forme dermatosis. Case series and review of the literature. J Dtsch Dermatol Ges. 2009; 7(2):102-107.

41. Winkelmann R, Scheen SR, Underdahl LO. Acanthosis nigricans and endocrine disease. JAMA. 1960;174(9):1145-1152.

42. Stuart CA, Peters EJ, Prince MJ, Richards G, Cavallo A, Meyer WJ. Insulin resistance with acanthosis nigricans: the roles of obesity and androgen excess. Metabolism. 1986;35(3):197-205.

43. Hud JA, Cohen JB, Wagner JM, Cruz PD. Prevalence and significance of acanthosis nigricans in an adult obese population. Arch Dermatol. 1992;128(7):941-944.

44. Burke JP, Hale DE, Hazuda HP, Stern MP. A quantitative scale of acanthosis nigricans. Diabetes Care. 1999;22(10):1655-1659.

45. Lopez-Alvarenga JC, Garcia-Hidalgo L, Landa-Anell MV, SantosGomez R, Gonzalez-Barranco J, Comuzzie A. Influence of skin color on the diagnostic utility of clinical acanthosis nigricans to predict insulin resistance in obese patients. Arch Med Res. 2006;37(6):744-748.

46. Kobaissi HA, Weigensberg MJ, Ball GDC, Cruz ML, Shaibi GQ, Goran MI. Relation between acanthosis nigricans and insulin sensitivity in overweight Hispanic children at risk for type 2 diabetes. Diabetes Care. 2004;27(6):1412-1416.

47. Pattamadilok B, Devpura S, Syed ZU, et al. Quantitative skin color measurements in acanthosis nigricans patients: colorimetry and diffuse reflectance spectroscopy. Photodermatol Photoimmunol Photomed. 2012;28(4):213-215

48. Colver GB, Mortimer PS, Millard PR, Dawber RP, Ryan TJ. The 'dirty neck' -a reticulate pigmentation in atopics. Clin Exp Dermatol. 1987; 12(1):1-4.

49. Seghers AC, Lee JS, Tan CS, et al. Atopic dirty neck or acquired atopic hyperpigmentation? An epidemiological and clinical study from the National Skin Centre in Singapore. Dermatology. 2014;229(3):174-182.
50. Park YJ, Kang HY, Lee ES, Kim YC. Differentiating confluent and reticulated papillomatosis from acanthosis nigricans. J Cutan Pathol. Epub 2015 Aug 12.

51. Jackson-Richards D. Confluent and reticulated ppillomatosis. In: Dermatology Atlas for Skin of Color. Springer; 2014:45-47.

52. Engin B, Kutlubay Z, Çelik U, Serdaroğlu S, Tüzün Y. HaileyHailey disease: a fold (intertriginous) dermatosis. Clin Dermatol. 2015;33(4):452-455.

53. Levi J. Case 2: a persistent hyperpigmented plaque on the neck. Paediatr Child Health. 2016;21(3):135.

54. Thomas RS, Collins J, Young RJ, Bohlke A. Atypical presentations of terra firma-forme dermatosis. Pediatr Dermatol. 2015;32(2):e50-e53.

55. Greywal T, Cohen PR. Terra firma-forme dermatosis: a report of ten individuals with Duncan's dirty dermatosis and literature review. Dermatol Pract Concept. 2015;5(3):29-33.

56. Lobstein T, Jackson-Leach R, Moodie ML, et al. Child and adolescent obesity: part of a bigger picture. Lancet. 2015;385(9986):2510-2520.

57. AMA House of Delegates. Resolution 420. Recognition of Obesity as a Disease. Available from: http://www.npr.org/documents/2013/jun/ ama-resolution-obesity.pdf. Accessed September 10, 2016.

58. Vash PD. Yes, obesity is a serious disease but it must also be taken seriously. Obesity (Silver Spring). 2014;22(7):1579.

59. Jarris PE. Obesity as disease: an opportunity for integrating public health and clinical medicine. J Public Health Manag Pract. 2013; 19(6):610-612.

60. Funk LM, Jolles SA, Voils CI. Obesity as a disease: has the AMA resolution had an impact on how physicians view obesity? Surg Obes Relat Dis. 2016;12(7):1431-1435.

61. Kyle TK, Dhurandhar EJ, Allison DB. Regarding obesity as a disease: evolving policies and their implications. Endocrinol Metab Clin North Am. 2016;45(3):511-520.

62. Hoyt CL, Burnette JL, Auster-Gussman L. "Obesity is a disease": examining the self-regulatory impact of this public-health message. Psychol Sci. 2014;25(4):997-1002.

63. Katz DL. Perspective: obesity is not a disease. Nature. 2014;508(7496): S57.

64. Gillman MW, Block JP. Children with obesity: how are they different? JAMA Pediatr. 2015;169(7):626-628.

65. Hoey H. Management of obesity in children differs from that of adults. Proc Nutr Soc. 2014;73(4):519-525.

66. Wickham EP 3rd, DeBoer MD. Evaluation and treatment of severe obesity in childhood. Clin Pediatr. 2015;54(10):929-940.

67. Gurnani M, Birken C, Hamilton J. Childhood obesity: causes, consequences, and management. Pediatr Clin North Am. 2015;62(4):821-840.

68. Swinburn BA, Sacks G, Hall KD, et al. The global obesity pandemic: shaped by global drivers and local environments. Lancet. 2011;378(9793):804-814.

69. Karnik S, Kanekar A. Childhood obesity: a global public health crisis. Int J Prev Med. 2012;3(1):1-7.

70. Rajeev SP, Wilding J. Etiopathogenesis of obesity. In: Obesity, Bariatric and Metabolic Surgery. Springer; 2016:13-20.

71. Hughes SO, Power TG, Dave JM, O'Connor TM. Childhood environment and obesity. In: Metabolic Syndrome: A Comprehensive Textbook. Springer International Publishing. 2016:243-259.

72. Atkinson RL. Current status of the field of obesity. Trends Endocrinol Metabol. 2014;25(6):283-284.

73. Zinn AR. Unconventional wisdom about the obesity epidemic. $A m$ JMed Sci. 2010;340(6):481-491.

74. Singh AS, Mulder C, Twisk JW, Van Mechelen W, Chinapaw MJ. Tracking of childhood overweight into adulthood: a systematic review of the literature. Obes Rev. 2008;9(5):474-488.

75. Simmonds M, Llewellyn A, Owen C, Woolacott N. Predicting adult obesity from childhood obesity: a systematic review and meta-analysis. Obes Rev. 2016;17(2):95-107.

76. Spruijt-Metz D. Etiology, treatment, and prevention of obesity in childhood and adolescence: a decade in review. J Res Adolesc. 2011;21(1):129-152. 
77. Juonala M, Magnussen CG, Berenson GS, et al. Childhood adiposity, adult adiposity, and cardiovascular risk factors. $N$ Engl J Med. 2011;365(20):1876-1885.

78. Daniels SR, Kelly AS. Pediatric severe obesity: time to establish serious treatments for a serious disease. Childhood Obes. 2014;10(4):283-284.

79. Kelly AS, Barlow SE, Rao G, et al. Severe obesity in children and adolescents: identification, associated health risks, and treatment approaches a scientific statement from the American Heart Association. Circulation. 2013;128(15):1689-1712.

80. Crocker MK, Yanovski JA. Pediatric obesity: etiology and treatment. Pediatr Clin North Am. 2011;58(5):1217-1240, xi.

81. Ayer J, Charakida M, Deanfield JE, Celermajer DS. Lifetime risk: childhood obesity and cardiovascular risk. Eur Heart J. 2015;36(22):1371-1376.

82. American Diabetes Association. 3. Foundations of care and comprehensive medical evaluation. Diabetes care. 2016;39(Suppl 1):S23-S35.

83. Rutkowski EM, Connelly CD. Adolescent obesity risk knowledge (AORK): let the discussion begin. J Spec Pediatr Nurs. 2016;21(1):37-43.

84. Puhl RM, Heuer CA. The stigma of obesity: a review and update. Obesity. 2009;17(5):941-964.

85. Puhl RM, Heuer CA. Obesity stigma: important considerations for public health. Am J Public Health. 2010;100(6):1019-1028.

86. Puhl RM, Phelan SM, Nadglowski J, Kyle TK. Overcoming weight bias in the management of patients with diabetes and obesity. Clin Diabetes. 2016;34(1):44-50.

87. Mackey ER, Olson A, DiFazio M, Cassidy O. Obesity prevention and screening. Primary care. 2016;43(1):39-51.

88. American College of Preventive Medicine. Adolescent obesity-time for a commitment to action. 2011. Available from: http://c.ymcdn.com/ sites/www.acpm.org/resource/resmgr/timetools-files/adolescentobesityclinicalref.pdf. Accessed September 10, 2016.

89. Stok FM, de Ridder DT, de Vet E, et al. Hungry for an intervention? Adolescents' ratings of acceptability of eating-related intervention strategies. BMC Public Health. 2016;16(1):5.

90. Brown CL, Halvorson EE, Cohen GM, Lazorick S, Skelton JA. Addressing childhood obesity: opportunities for prevention. Pediatr Clin North Am. 2015;62(5):1241-1261.

91. Heilbron N, Prinstein MJ. Peer influence and adolescent nonsuicidal self-injury: a theoretical review of mechanisms and moderators. Appl Prevent Psychol. 2008;12(4):169-177.

92. Baxter KA, Ware RS, Batch JA, Truby H. Predicting success: factors associated with weight change in obese youth undertaking a weight management program. Obes Res Clin Pract. 2013;7(2):e147-e154.

93. Seibert TS, Allen DB, Carrel AL. Adolescent obesity and its risks: how to screen and when to refer. J Clin Outcomes Manag. 2014;21(2):87-96.

94. Nguyen TT, Keil MF, Russell DL, et al. Relation of acanthosis nigricans to hyperinsulinemia and insulin sensitivity in overweight African American and white children. J Pediatr. 2001;138(4):474-480.

95. Hirschler V, Aranda C, Oneto A, Gonzalez C, Jadzinsky M. Is acanthosis nigricans a marker of insulin resistance in obese children? Diabetes Care. 2002;25(12):2353.

96. Burgio E, Lopomo A, Migliore L. Obesity and diabetes: from genetics to epigenetics. Mol Biol Rep. 2015;42(4):799-818.

97. Kao K-T, Sabin MA. Type 2 diabetes mellitus in children and adolescents. Aust Fam Phys. 2016;45(6):401

98. D'Adamo E, Caprio S. Type 2 diabetes in youth: epidemiology and pathophysiology. Diabetes Care. 2011;34(Supp1 2):S161-S165.

99. Sylvetsky-Meni AC, Gillepsie SE, Hardy T, Welsh JA. The impact of parents' categorization of their own weight and their child's weight on healthy lifestyle promoting beliefs and practices. J Obes. 2015;2015:307381.

100. Park MH, Falconer CL, Croker H, et al. Predictors of health-related behaviour change in parents of overweight children in England. Prevent Med. 2014;62:20-24.

101. Rey-Lopez JP, de Rezende LF, Pastor-Valero M, Tess BH. The prevalence of metabolically healthy obesity: a systematic review and critical evaluation of the definitions used. Obes Rev. 2014;15(10):781-790.

102. Małecka-Tendera E. Healthy obese child: when and in whom do comorbidities develop? Nutr Obes Metabol Surg. 2014;1:10-13.
103. Eckel N, Meidtner K, Kalle-Uhlmann T, Stefan N, Schulze MB Metabolically healthy obesity and cardiovascular events: a systematic review and meta-analysis. Eur J Prev Cardiol. 2016;23(9): 956-966.

104. Puri R. Is it finally time to dispel the concept of metabolically-healthy obesity? J Am Coll Cardiol. 2014;63(24):2687-2688.

105. Rey-Lopez JP, de Rezende LF, de Sa TH, Stamatakis E. Is the metabolically healthy obesity phenotype an irrelevant artifact for public health? Am J Epidemiol. 2015;182(9):737-741.

106. Wen M, Su D. Correlates of leisure-time physical activity participation among Latino children and adolescents with acanthosis nigricans. J Immigr Minor Health. 2015;17(5):1330-1336.

107. Baselga Torres E, Torres-Pradilla M. Cutaneous manifestations in children with diabetes mellitus and obesity. Actas Dermosifiliogr. 2014;105(6):546-557.

108. Venkatswami S, Anandam S. Acanthosis nigricans: a flag for insulin resistance. J Endocrinol Metabol Diabetes South Africa. 2014;19(2):68-74.

109. Caceres M, Teran CG, Rodriguez S, Medina M. Prevalence of insulin resistance and its association with metabolic syndrome criteria among Bolivian children and adolescents with obesity. BMC Pediatrics. 2008;8:31.

110. Santoro N, Amato A, Grandone A, et al. Predicting metabolic syndrome in obese children and adolescents: look, measure and ask. Obes Facts. 2013;6(1):48-56.

111. Hardin DS. Screening for type 2 diabetes in children with acanthosis nigricans. Diabetes Educ. 2006;32(4):547-552.

112. Scott LK, Hall LM. Reliability and validity of the acanthosis nigricans screening tool for use in elementary school-age children by school nurses. J Sch Nurs. 2012;28(6):442-447.

113. Otto DE, Wang X, Garza V, Fuentes LA, Rodriguez MC, Sullivan P. Increasing body mass index, blood pressure, and acanthosis nigricans abnormalities in school-age children. J Sch Nurs. 2013;29(6): 442-451

114. Law J, Northrup K, Wittberg R, Lilly C, Cottrell L. Observing anthropometric and acanthosis nigrican changes among children over time. J Sch Nurs. 2013;29(6):435-441.

115. Jones LH, Ficca M. Is acanthosis nigricans a reliable indicator for risk of type 2 diabetes? J Sch Nurs. 2007;23(5):247-251.

116. Yamazaki H, Ito S, Yoshida H. Acanthosis nigricans is a reliable cutaneous marker of insulin resistance in obese Japanese children. Pediatr Int. 2003;45(6):701-705.

117. Drobac S, Brickman W, Smith T, Binns HJ. Evaluation of a type 2 diabetes screening protocol in an urban pediatric clinic. Pediatrics. 2004;114(1):141-148.

118. Copeland KC, Silverstein J, Moore KR, et al. Management of newly diagnosed type 2 diabetes mellitus (T2DM) in children and adolescents. Pediatrics. 2013;131(2):364-382.

119. American Diabetes Association. 2. Classification and diagnosis of diabetes. Diabetes Care. 2016;39(Suppl 1):S13-S22.

120. Brickman WJ, Huang J, Silverman BL, Metzger BE. Acanthosis nigricans identifies youth at high risk for metabolic abnormalities. $J$ Pediatr. 2010;156(1):87-92.

121. Urrutia-Rojas X, McConathy W, Willis B, et al. Abnormal glucose metabolism in Hispanic parents of children with acanthosis nigricans. ISRN Endocrinol. 2011;2011:481371.

122. Wang C-H, Lin W-D, Bau D-T, Chou I-C, Tsai C-H, Tsai F-J. Appearance of acanthosis nigricans may precede obesity: an involvement of the insulin/IGF receptor signaling pathway. BioMedicine. 2013;3(2):82-87.

123. Kapoor S. Diagnosis and treatment of acanthosis nigricans. Skinmed. 2010;8(3):161-164.

124. Murphy-Chutorian B, Han G, Cohen SR. Dermatologic manifestations of diabetes mellitus: a review. Endocrinol Metab Clin North Am. 2013;42(4):869-898.

125. Kuroki R, Sadamoto Y, Imamura M, et al. Acanthosis nigricans with severe obesity, insulin resistance and hypothyroidism: improvement by diet control. Dermatology. 1999;198(2):164-166. 
126. Sarwer DB, Dilks RJ. Invited commentary: childhood and adolescent obesity: psychological and behavioral issues in weight loss treatment. J Youth Adolesc. 2012;41(1):98-104.

127. Lenders CM. Paediatric obesity: can medications help. Curr Opin Endocrinol Diabetes Obes. 2015;22(5):331-339.

128. Taylor SR. Management of adolescent obesity. US Pharm. 2015;40(5):35-38

129. Daneschvar HL, Aronson MD, Smetana GW. FDA approved antiobesity drugs in the United States. Am J Med. 2016;129(8):879.e1-e6.

130. Kendall DL, Amin R, Clayton PE. Metformin in the treatment of obese children and adolescents at risk of type 2 diabetes. Pediatric Drugs. 2014; 16(1):13-20.

131. Hsia Y, Dawoud D, Sutcliffe AG, Viner RM, Kinra S, Wong IC. Unlicensed use of metformin in children and adolescents in the UK. $\mathrm{Br} J$ Clin Pharmacol. 2012;73(1):135-139.
132. Mirensky TL. Bariatric surgery in youth. Endocrinol Metab Clin North Am. 2016;45(2):419-431.

133. Paulus GF, de Vaan LE, Verdam FJ, Bouvy ND, Ambergen TA, van Heurn LW. Bariatric surgery in morbidly obese adolescents: a systematic review and meta-analysis. Obes Surg. 2015;25(5):860-878.

134. Desai NK, Wulkan ML, Inge TH. Update on adolescent bariatric surgery. Endocrinol Metab Clin North Am. 2016;45(3):667-676.

135. McGinty S, Richmond TK, Desai NK. Managing adolescent obesity and the role of bariatric surgery. Curr Opin Pediatr. 2015;27(4):434-441.

136. Hofmann B. Bariatric surgery for obese children and adolescents: a review of the moral challenges. BMC Med Ethics. 2013;14:18.

137. Childerhose JE, Tarini BA. Understanding outcomes in adolescent bariatric surgery. Pediatrics. 2015;136(2):e312-e314.

138. Hutchinson J, Emerick J, Saxena H. The future of pediatric obesity. Prim Care. 2016;43(1):1-17.
Adolescent Health, Medicine and Therapeutics

\section{Publish your work in this journal}

Adolescent Health, Medicine and Therapeutics is an international, peer-reviewed, open access journal focusing on health, pathology, and treatment issues specific to the adolescent age group. All aspects of health maintenance, preventative measures and disease treatment interventions are addressed within the journal and practitioners from all disciplines are

\section{Dovepress}

invited to submit their work as well as healthcare researchers and patient support groups. This journal is included in PubMed. The manuscript management system is completely online and includes a very quick and fair peer-review system. Visit http://www.dovepress.com/testimonials. php to read real quotes from published authors.

Submit your manuscript here: http://www.dovepress.com/adolescent-health-medicine-and-therapeutics-journal 